man on some phenomena of the upper atmosphere and M. H. L. Pryce on nuclear hyperfine structure of paramagnetic resonance. A complete list of the papers, together with abstracts, is given in the minutes of the meeting, which are printed in the April 15 issue of the Physical Review $(82,291 ; 1951)$.

It was reported that the membership was 9,740 , and that the income of the Society had exceeded expenditure by a substantial amount, but that there was little hope that the Society would be equally fortunate during 1951. A change in the by-laws was approved which empowered the Council to fix the terms on which members of the Society shall receive either Physics Abstracts or Engineering Abstracts. The subscription prices at which these journals are sold to the Society by the Institution of Electrical Engineers, London, have recently been raised, and the purpose of the amended by-law is to enable the Council to recover the extra cost. A committee was appointed to make recommendations about the future relations of the Society and Science Abstracts.

The minutes include a copy of the letter sent by Dr. D. W. Bronk, president of the National Research Council, on December 11, 1950, to R. L. Clark, the director of the Manpower Office of the National Security Resources Board, in which specific recommendations with regard to the question of scientific man-power in the United States of America, the setting up of a National Scientific Personnel Board and the establishment of a register of professionally qualified scientific workers are outlined. The Council of the Physical Society formally approved of these recommendations.

\section{MOVEMENT OF SWIFTS IN SUMMER}

$\mathrm{T}$

HE year 1950 was a good one for studying the movements of swifts (Apus apus), and during the year the movements of forty thousand birds were recorded : a report on the observations has been made by H. G. Hurrell and recently described in British Birds (44, No. 5 ; May 1951).

Movements were found to take place not only during arrival and departure but also in the middle of the breeding season as well. The date when movement occurs is the main reason for classifying it as immigration, emigration or a movement occurring between the two. There is no certain way of distinguishing movements in the field, although there is a tendency for larger numbers of birds to group together when they are leaving Great Britain.

Swifts appear to penetrate the country from the south and work northwards. Arrivals over many years average a day or two earlier in the south than in the south-east. The east coast as a rule is reached rather late and usually in such small numbers that there is little to indicate any spring passage of swifts from the British Isles to other countries.

It is difficult to say when the arrival period ends because movements which have a migratory appearance may take place at any time while swifts are in Britain. Large movements occur in June and early July. These are thought to be undertaken because unfavourable weather forces the swift to seek regions with more adequate food supplies; the food of the swift is adversely affected by the passage of a cyclone or depression.

In 1947 Koskimies suggested that the birds tried to avoid an advancing depression by flying against the wind round the south-east side of it, and that these weather movements are undertaken by first-year nonbreeding swifts and, to a varying extent, by the breeding birds. If mid-season movements were always bad-weather movements, a comparison of the data with meteorological records should show some kind of broad correlation. At times this could be found; but there are cases when there is no obvious connexion between major movements and low temperatures or low pressures. The 1950 mid-breeding season records took place at a time whon weather conditions were comparatively stable and an anticyclone was maintaining fine warm weather over most of the British Isles. Nor is there clear evidence that the birds. taking part in these woather movements are firstyear non-breeding swifts. As yet the evidence is insufficient to say whether large mid-season movements are composed mainly of British swifts or of swifts which have just arrived from overseas.

It is impossible to say when emigration begins, since it commences during July when mid-season movements may still be taking place. Many breeding and most non-breeding swifts leave during July. During this month in 1950 swifts were frequently on the move, while August showed an almost complete absence of any swifts flying northwards; the main directions were south or south-west. Early in August the British Isles are practically drained of breeding swifts. Yet quite large numbers were recorded throughout the month at favoured spots, especially on the east coast. During the last ten days of August, there was a widespread and, for the time of the year, remarkably strong wave. Such large numbers on these late dates are surprising, and it is suspected that these are largely swifts from other countries in more northerly latitudes visiting Britain on their return passage.

In another article in the same issue of British Birds ("The Use of Mobile Observers in the Study of Patterns of Migration"), Arnold Darlington criticizes much of the work on the migration of swifts which has been done in recent years because observations have been made at fixed vantage points, a method which has inherent in it several possible errors.

These errors are reduced if watchers deploy over an area and attempt to locate the main concentrations of swifts and to follow up any flight-lines radiating from them. The use of mobile squads of observers operating on bicycles has proved particularly useful, skilled riders being able to ride at a speed greater than the ground-speed of a migrant swift. In May 1950 the use of fifty-seven cyclists experienced in this mobile method of observation and operating in nineteen units enabled an intensive study to be made of the distribution of migrating swifts passing through south Cambridgeshire. From their results it would appear that, first, in anticyclonic, stable conditions, with light wind and mild temperatures, the movement of swifts tends to follow individual tracks and, although flight-lanes may be followed to some extent, they are not immediately apparent and may require careful seeking. The swifts tend, however, to be attracted by certain places, and here the flight-lanes may become concentrated and obvious, often persisting in their essential form for days on end. Second, in more unsettled conditions, with strong wind, low temperatures and cloud, the swifts may take to watercourses in great numbers, flying low and tending to 'pile up' in some places.

T. H. HAWKINS 